\title{
Reconstruction of Long Segmental Tibial Bone Defect Using the Bone Transport Compared to Acute Shortening and Re-lengthening : A Retrospective Study
}

\section{Feiyu Cai}

the First Affiliated Hospital of Xinjiang Medical University

Yanshi Liu

the First Affiliated Hospital of Xinjiang Medical University

Kai Liu

the First Affiliated Hospital of Xinjiang Medical University

Chenchen Fan

the First Affiliated Hospital of Xinjiang Medical University

Xiayimaierdan Maimaiti

the First Affiliated Hospital of Xinjiang Medical University

Aihemaitijiang Yusufu ( $\sim$ ahmatjang@163.com )

the First Affiliated Hospital of Xinjiang Medical University

\section{Research Article}

Keywords: acute shortening, bone defect, bone transport, limb lengthening, Ilizarov technique

Posted Date: August 11th, 2021

DOl: https://doi.org/10.21203/rs.3.rs-783176/v1

License: (c) (i) This work is licensed under a Creative Commons Attribution 4.0 International License.

Read Full License 


\section{Abstract}

Background: Ilizarov technique has been widely used to salvage bone defects. However, treating large bone defects remains a challenge for surgeons. The aim of this study was to compare bone transport with acute shortening/re-lengthening in a series of large tibial segmental defects.

Method: A total of 39 patients (29 males, 10 females) with large tibial segmental defects were treated with the llizarov technique (Group A: bone transport in 23 cases; Group B: acute shortening/re-lengthening 16 in cases) from March 2010 to December 2018. The mean age was 38.7 years (range24 years to 55 years). The average bone defect size was $8.82 \mathrm{~cm}$ (range from $6 \mathrm{~cm}$ to $12 \mathrm{~cm}$ ). The demographic data, operation duration, docking time, external fixation time, and external fixation index were retrospectively documented and analyzed. Complications that occur during the treatment were classified. The clinical outcomes were evaluated by the Association for the Study and Application of the Method of llizarov criteria (ASAMI) at the last clinical visit.

Result: There were no statistically significant differences $(P>0.05)$ in the demographic data of the two groups. There was no significant difference in operation duration between the two groups. The docking time in group $A$ was longer than that in group $B(93.26 \pm 19.52$ days, $58.44 \pm 14.23$ days, $P<0.001)$. No statistical significance was obversed for the external fixation time in the two groups $(330.87 \pm 88.52$ days in group $A, 321.25 \pm 56.67$ days in group $B, P=0.704)$. A higher external fixation index was presented in group $A(38.32 \pm 5.39$ days $/ \mathrm{cm})$ than group $B(35.17 \pm 2.14$ days $/ \mathrm{cm})(P=0.033)$. There was no significant difference between the two groups in ASAMI bone results and functional results (Table 4). Complications were more prevalent in group A (28 complications of 23 patients), while less in group B (7 complications of 16 patients $)(P<0.05)$.

Conclusion: Both bone transport and acute shortening/re-lengthening technique can achieve satisfactory clinical outcomes in the reconstruction of long segmental tibial bone defect caused by infection using a monolateral rail external fixator. The acute shortening/re-lengthening can significantly decrease the docking time, external fixation index, and complications compared with bone transport.

\section{Background}

Bone defects of the tibia have always been extremely difficult to manage successfully, and this challenge may be increased when the critical defects were present [1-3]. Additional necrotic bone resection was needed to eradicate an active infection nidus in patients with chronic osteomyelitis, who often suffered high energy trauma and multiple prior surgical procedures [4, 5]. Patients with severe soft-tissue injuries, shortening deformity of the lower limb, or functional loss acquired poor clinical outcomes.

Several surgical options have been proposed for patients with segmental tibial bone defects combined with infection or not, such as cancellous bone grafting, vascularized free-tissue transfers, and bone grafts combined with microvascular tissue transfers [1, 6-10]. However, it is difficult to achieve satisfactory alignment and limb length via these methods due to the limitation of soft-tissue conditions. In the llizarov 
technique, the bone healing was stimulated by the pulling tension using the external fixator via corticotomy, which can regenerate new bone without the necessity of bone grafting, and the alignment and limb length can be reconstructed preferably $[2,11,12]$. The llizarov technique has been used for more than 30 years successfully since it was first mentioned $[13,14]$. This technique was used in two different ways to salvage limbs, including bone transport and acute shortening/re-lengthening [15-19]. The procedure of bone transport is that a normal segment of bone is gradually transported from the adjacent area to the bone defect area, and the transported segment is mineralized to form new bone tissue, so as to achieve the purpose of bone reconstruction $[7,8,15-17,20]$. In this process, the external fixator is managed to gradually transport the bone segment under the controlled mechanical rate (about 1.00 $\mathrm{mm} /$ day) $[13,14]$. For patients with bone transport, the length of the limb does not change, and the transported segment is equal to the bone defect.

Acute shortening/re-lengthening is characterized by shortening of the limb and closing the bone defect $[7-9,19,21-23]$. The shortening deformity is restored gradually by bone lengthening using an external fixator under a similar rate (about $1.00 \mathrm{~mm} /$ day) $[13,14]$. In patients with acute shortening/relengthening, the stability of bone fixation can be enhanced by the early contact of the original area of bone loss, and the docking site can be met directly $[7-9,19,21-23]$.

Bone transport is often used to treat cases with large bone defects, and patients with small bone defects are generally managed by acute shortening/re-lengthening. However, patients with a long segmental bone defect who underwent the bone transport may suffer the axial deviation, long docking time, delayed union, or non-union [24, 25]. And patients who underwent acute shortening/re-lengthening may experience various soft-tissue complications. The purpose of this study was retrospectively compared bone transport with acute shortening/re-lengthening (the size of acute shortening was adjusted according to the soft tissue condition) in the treatment of long segmental tibial bone defects, and determined the most appropriate individualized treatment to reduce the common complications.

\section{Materials And Methods}

This retrospective study was based on hospital records and analysis of routine radiographs obtained during the course of treatment from March 2010 to December 2018. A total of 39 patients with posttraumatic tibial infected non-unions or chronic osteomyelitis with a bone loss between 6 and $12 \mathrm{~cm}$ were included in this study. Patients with an incomplete record, follow-up was less than two years, poor compliance, bone tumor, and any other illness that can affect bone healing (such as diabetes) were excluded in this study. All patients were managed by the llizarov technique using the monolateral rail external fixator (Limb Reconstruction System, LRS, Orthofix, Verona, Italy), either by bone transport or acute shortening/re-lengthening. The surgical selection was based on clinical parameters according to soft tissue condition, bone defect size, patient's wishes, and surgeon judgment.

A total of 39 patients ( 29 males, 10 females) with an average age of $38.74 \pm 9.19$ years (range from 24 years to 55 years) in this study were divided into two groups (Group A: bone transport, $n=23$; Group B: 
acute shortening/re-lengthening, $n=16$ ). Meticulous debridement of the affected tissues, installation of a monolateral rail external fixator, and a percutaneous minimally invasive cortical osteotomy using the Gigli saw were performed in all the patients. The principal outcome measure was operation duration, docking time, external fixation time (EFT), and the external fixation index (EFIXEFT/the length of bone regenerated). Clinical outcomes were evaluated by the Study and Application of the Method of Ilizarov criteria (ASAMI) [26] at the last follow-up. Complications were recorded and analyzed, and then the total complications and mean complications/patient were used to compare the outcomes of the two groups.

\section{Surgical procedure}

All the surgical procedures were performed by the same team. The patients were positioned supine on a radiolucent table under continuous general or regional anesthesia. The incision was carried down to the periosteum correspond to the previous surgical incisions when possible, protecting the healthy skin or subcutaneous tissues. The infected and devitalized bone and soft tissues were radically resected after complete hardware removal, and the samples were sent to culture for the sensitive antibiotics. The bony ends were resected until cortical bleeding, called the paprika sign [26], which manifests healthy osseous tissue. Frequent alternating irrigation with hydrogen peroxide, physiological saline, and iodine liquid during after debridement is critical.

Antibiotic-impregnated cement beads were applied for the patients with severe infection. Meticulous hemostasis was performed before wound closure. The vacuum sealing drainage (VSD) technique was used for cases with soft tissue defects or those that could not be initially closed without tension.

\section{Bone transport}

Length and axis restoration of the injured extremity was achieved firstly when the monolateral external fixator was installed. Two or three Schanz screws fixed by the connecting rail were inserted on the proximal and distal bony ends, respectively. For the patients with bone transport, the other two screws were inserted on the planned transport bony fragment and fixated at the sliding block. Every screw needed to be on the same plane. According to the location of the bone defect, a percutaneous cortical osteotomy with minimal invasion was conducted using Gigli saw. One osteotomy was performed on each side of the defect when the patient suffered a central defect (converging transport) (Figure 1).

\section{Acute shortening/re-lengthening}

For all patients in this group, the acute shortening was managed on the injured limb at a suitable size according to the patient's soft tissue and bone condition when the monolateral external fixator was installed. The tibia and fibula should be fixed together at the upper and lower sliding block to prevent asynchronous lengthening and dislocation during limb extension. Then the osteotomy procedure was performed on each side of the defect. After the docking site comes into contact via bone transport, the limb lengthening was performed until there was no limb discrepancy in the bilateral extremities (Figure 2$5)$. 


\section{Post-operative management}

Sensitive antibiotic therapy was conducted by oral or intravenous injection until the infection been resolved depending on the clinical manifestations and laboratory indicators. The small soft tissue defects were treated by direct suture or local tissue flap. The larger soft tissue defects were managed by free skin grafting or flap transfer.

All patients were encouraged to undergo the isometric muscle and joint range of motion (ROM) exercise on the postoperative second day, and early full-weight-bearing was also encouraged. The foot was kept in a neutral position using a rigid shoe with an elastic band, preventing ankle-equines contractures. Regular pin site care was performed every day using medical alcohol or iodophors.

After a 7 days latency period, bone transport started at a rate of $1 \mathrm{~mm} / \mathrm{d}(0.25 \mathrm{~mm} / 6 \mathrm{~h})$. Notably, the transport speed was modified according to the patient's tolerance and the radiological quality of the regenerate. After docking, bone transport continued for 4 or 5 days to compress the docking site, and regenerate was allowed to consolidation. For patients who require limb lengthening, the same rate of 1 $\mathrm{mm} / \mathrm{d}(0.25 \mathrm{~mm} / 6 \mathrm{~h})$ was conducted until there was no limb discrepancy in the bilateral extremities.

During the bone transport and limb lengthening phases, the regular clinical visit was performed twice a month, while monthly in the consolidation period. The monolateral external fixator was dynamized and followed by removal when the satisfactory consolidation (three uninterrupted cortices appeared at the distraction zone) and docking site complete union were achieved on the standard anteroposterior (AP) and lateral radiographs. After the frame removal, a functional brace was used to prevent re-fracture at the docking site or bending in the distraction zone.

\section{Statistical analysis}

Statistical analysis was performed with the SPSS 22.0 (IBM Corp, USA). Independent-samples T-tests were used to analyze the continuous variables, which were expressed as the mean, standard deviation (SD), and range of the observations. The count variables were analyzed by the Chi-square or Fisher's test, expressing as a number. A statistically significant difference was set at $P<0.05$.

\section{Results}

A total of 39 patients with bone defects measuring between 6 to $12 \mathrm{~cm}$ were included in this study. The infected non-union was presented in 13 cases, and the chronic osteomyelitis in 26 cases. All patients underwent multiple debridements. Group A consisted of 23 patients managed by bone transport, and group $B$ consisted of 16 patients managed by acute shortening/re-lengthening. There were no statistically significant differences $(P>0.05)$ in the demographic data of the two groups (Table 1). The average size of bone defect was $8.57 \mathrm{~cm}$ in group $A$ and $9.19 \mathrm{~cm}$ in group B (Table 1). The specific information of group B was shown in Table 2. And the typical case in group B was illustrated in Fig. 3-5. 
Table 1

Demographic data of patients included in the present study

\begin{tabular}{|c|c|c|c|c|}
\hline & Group A & Group B & Total & P-value \\
\hline Patients & 23 & 16 & 39 & \\
\hline Age (year) & $38.17 \pm 9.14$ & $39.56 \pm 8.59$ & $38.74 \pm 9.19$ & 0.649 \\
\hline Sex & & & & 0.939 \\
\hline Male & 17 & 12 & 29 & \\
\hline Female & 6 & 4 & 10 & \\
\hline Injured side & & & & 0.773 \\
\hline Lift & 9 & 7 & 16 & \\
\hline Right & 14 & 9 & 23 & \\
\hline Etiology of bone defect & & & & 0.818 \\
\hline Infected nonunion & 8 & 5 & 13 & \\
\hline Chronic osteomyelitis & 15 & 11 & 26 & \\
\hline Location of bone defect & & & & 0.854 \\
\hline Proximal & 4 & 2 & 6 & \\
\hline Middle & 11 & 9 & 20 & \\
\hline Distal & 8 & 5 & 13 & \\
\hline Defect size $(\mathrm{cm})$ & $8.57 \pm 1.46$ & $9.19 \pm 1.8$ & $8.82 \pm 1.62$ & 0.242 \\
\hline \multicolumn{5}{|l|}{ Group A: Bone transport } \\
\hline Group B: Acute shortenir & /re-lengthenins & & & \\
\hline
\end{tabular}


Table 2

The specific information of acute shortening/re-lengthening group

\begin{tabular}{|llll|}
\hline Patients & Bone defect $(\mathbf{c m})$ & Acute shortening $(\mathbf{c m})$ & Bone defect after acute shortening $(\mathbf{c m})$ \\
\hline 1 & 9.0 & 3.0 & 6.0 \\
\hline 2 & 8.0 & 3.0 & 5.0 \\
\hline 3 & 7.0 & 2.0 & 5.0 \\
\hline 4 & 9.0 & 4.0 & 5.0 \\
\hline 5 & 6.0 & 3.0 & 3.0 \\
\hline 6 & 6.5 & 3.5 & 3.0 \\
\hline 7 & 9.0 & 3.0 & 6.0 \\
\hline 8 & 9.0 & 3.0 & 7.0 \\
\hline 9 & 9.5 & 4.0 & 5.5 \\
\hline 10 & 12.0 & 6.0 & 6.0 \\
\hline 11 & 10.5 & 3.0 & 7.5 \\
\hline 12 & 11.0 & 3.0 & 8.0 \\
\hline 13 & 11.0 & 4.0 & 7.0 \\
\hline 14 & 8.5 & 2.0 & 6.5 \\
\hline 15 & 12.0 & 5.0 & 7.0 \\
\hline 16 & 9.0 & 3.0 & 6.0 \\
\hline & & & \\
\hline
\end{tabular}

The comparison of the therapeutic process in two groups was shown in Table 3. There was no significant difference in operation duration between the two groups. The docking time in group $A$ was longer than that of group $B(93.26 \pm 19.52$ days, $58.44 \pm 14.23$ days, $P<0.001)$. Although the external fixation time was no different in the two groups (330.87 \pm 88.52 days in group $A ; 321.25 \pm 56.67$ days in group $B)(P=$ $0.704)$, there was a significant difference in external fixation index between group $A(38.32 \pm 5.39)$ and group B $(35.17 \pm 2.14)(P=0.033)$. 
Table 3

Comparison of the results in the two groups

\begin{tabular}{|lllll|}
\hline & Group A & Group B & Mean & P-value \\
\hline Operation duration (mins) & $156.52 \pm 23.67$ & $149.38 \pm 21.44$ & $153.59 \pm 22.77$ & 0.343 \\
\hline Docking time (days) & $93.26 \pm 19.52$ & $58.44 \pm 14.23$ & $78.97 \pm 24.53$ & 0.001 \\
\hline External Fixation Time (days) & $330.87 \pm 88.52$ & $321.25 \pm 56.67$ & $326.92 \pm 76.34$ & 0.704 \\
\hline External Fixation Index (days/cm) & $38.32 \pm 5.39$ & $35.17 \pm 2.14$ & $37.02 \pm 4.59$ & 0.033 \\
\hline Group A: Bone transport & & & & \\
Group B: Acute shortening/re-lengthening & & & \\
\hline
\end{tabular}

The clinical outcomes and complications in the two groups were compared and illustrated in Table 4-5. According to bone results, in group A, there were excellent in 7 patients, good in 11, fair in 1, and poor in 1. In group $B$, there were excellent in 8 patients, good in 6 , and fair in 2 . According to Functional results, in group A, there were excellent in 6 patients, good in 13, and fair in 4. In group B, there were excellent in 6 patients, good in 7 , and fair in 3 . There was no significant difference between the two groups in bone results and functional results (Table 4). Complications were more prevalent in group A (28 complications of 23 patients), while less in group B (7 complications of 16 patients) $(P<0.05)$. More details are manifested in Table 5.

Table 4

Results of ASAMI scores

\begin{tabular}{|llllll|}
\hline Parameter & Excellent & Good & Fair & Poor & P-value \\
\hline Bone results & & & & & 0.570 \\
\hline Group A & 7 & 11 & 4 & 1 & \\
\hline Group B & 8 & 6 & 2 & 0 & \\
\hline Functional results & 6 & & & & 0.701 \\
Group A & 6 & 73 & 3 & 0 & \\
Group B & 7 & & & \\
Group A: Bone transport & & & & \\
Group B: Acute shortening/re-lengthening & & & \\
Bone result outcome criteria: union, infection, alignment, limb length discrepancy (LLD) \\
Functional result outcome criteria: pain, limp, range of motion (ROM), orthosis, and contracture
\end{tabular}


Table 5

Summary of complications in the two groups

\begin{tabular}{|llll|}
\hline Complications & Group A & Group B & P-value \\
\hline Pin tract infection (N/\%) & $3(13.04)$ & $2(12.5)$ & \\
\hline Axial deviation (N/\%) & $5(21.74)$ & $1(6.25)$ & \\
\hline Docking malalignment (N/\%) & $6(26.09)$ & $1(6.25)$ & \\
\hline Soft tissue incarceration (N/\%) & $4(17.39)$ & $1(6.25)$ & \\
\hline Joint stiffness (N/\%) & $5(21.74)$ & $2(12.5)$ \\
\hline Delayed union (N/\%) & $4(17.39)$ & $0(0.00)$ \\
\hline Nonunion (N/\%) & $1(4.35)$ & $0(0.00)$ \\
\hline Re-fracture (N/\%) & $0(0.00)$ & $0(0.00)$ \\
\hline Total complications (N/\%) & $28(121.74)$ & $7(43.75)$ & 0.046 \\
\hline Mean complications/patient & 1.22 & 0.44 \\
\hline Group A: Bone transport & & & \\
Group B: Acute shortening/re-lengthening & \\
\hline
\end{tabular}

\section{Discussion}

The segmental bone defect that was caused by infected non-union and chronic osteomyelitis is a formidable challenge, and limb salvage by multiple operations can be frustrating for the patient. Distraction osteogenesis (DO) is a technique mentioned by llizarov, in which bone regeneration occurs when subjected to tensile stress, contributes to managing this complex problem [13]. This technique has been reported to be particularly effective in the reconstruction of the significant bone loss $[17,27]$. Bone transport and acute shortening/re-lengthening both can be regarded as effective methods to reconstruct the bone defect caused by infected non-union or chronic osteomyelitis using the element of DO $[13,14]$. For patients with the two methods, the gradual mechanical distraction was performed at the segment of bone lengthening using the external fixator, and the segmental bone defect was replaced by new bone at the segment of bone lengthening, avoiding the large segmental bone grafts.

Bone transport technique has been widely used to reconstruct bone defects for decades [28-32]. Various forms of bone transport have been developed, the most common of which were bifocal bone transport and trifocal bone transport [28, 30,31]. Trifocal bone transport was based on bifocal bone transport with the addition of an osteotomy and extension segment to accelerate the defect closure and shorten the treatment duration. In patients with this procedure, the closure time of bone defect is decreased to $50 \%$ theoretically, and the total treating time is reduced accordingly [26]. However, more Schanz screws 
fixation and osteotomy may increase the incidence of pin tract infections and bring more trauma to patients. Hence, patients with bifocal bone transport were included in this study.

Acute shortening/re-lengthening has also been used to reconstruct post-traumatic segmental bone loss successfully in many previous studies [7-9, 15, 19, 21-23]. Although the method requires less time to complete closure of the bone defect and consolidation of docking sites, the acute shortening larger than $3 \mathrm{~cm}$ may result in complex complications, such as local arterial occlusion, a large limb length discrepancy, a long treatment duration, and even vascular and nerve palsy, which finally lead to the failed reconstruction $[9,11,33,34]$. A retrospective comparison between bone transport and acute shortening/re-lengthening was conducted by Kevin et al.,demonstrating that fewer complications were associated with acute shortening/re-lengthening [35]. However, there was a significant difference in the bone defect size between the bone transport group (average bone defect $7.0 \mathrm{~cm}$ ) and the acute shortening/re-lengthening group (average bone defect $5.8 \mathrm{~cm}$ ). Similar results also report by Mahaluxmivala et al. although plagued by some of the same limitations [22]. In this study, patients who underwent the bone transport or acute shortening/re-lengthening techniques were not exposed to the significant difference in the bone defect size $(P=0.242)$.

The most important finding of this study was that very similar outcomes were achieved with either bone transport or acute shortening/re-lengthening. However, the total number of complications per patient was significantly greater in the bone transport group compared to the acute shortening/re-lengthening group. Furthermore, although there was no difference in external fixation time between the two groups (group A, $330.87 \pm 88.52$ days; group $B, 321.25 \pm 56.67$ days), there was an advantage in external fixation index with the acute shortening/re-lengthening group $(35.17 \pm 2.14$ days $/ \mathrm{cm})$ compared to bone transport group $(38.32 \pm 5.39$ days $/ \mathrm{cm})$. These results may be related to the additional treatment for delayed union or non-union in the bone transport group.

There was a clear advantage that patients with acute shortening/re-lengthening have less docking time (58.44 \pm 14.23 days) compared to bone transport (93.26 \pm 19.52 days). Early docking promotes more rapid union, while compression in the re-lengthening process enhances the mechanical stability of the bone-fixator composite construct which was associated with a fewer possibility to develop axial deviation, docking malalignment, and soft tissue incarceration $[19,23,28]$. Previous studies have demonstrated that acute shortening/re-lengthening is preferable for smaller defects less than $3 \mathrm{~cm}$ in size $[19,22,28,35]$. However, for defects from 6 to $12 \mathrm{~cm}$, the acute shortening may be considered according to the soft tissue condition. In this study, 16 patients with acute shortening from 3 to $6 \mathrm{~cm}$ were observed retrospectively. Three patients developed to axial deviation, docking malalignment, and soft tissue incarceration respectively in acute shortening/re-lengthening group, less than bone transport group with axial deviation was presented in 5 patients, docking malalignment in 6 patients, and soft tissue incarceration in 4 patients.

In large bone defects, the axial contractive force of muscle tissue contributes to a certain size of limb shortening which may have little effect on local blood circulation. However, the excessive shortening and 
soft tissue separation for the closure of bone defect may form the organization lacuna at the docking site, which can destroy the local blood circulation and affect the union of the docking site. Therefore, a suitable size of limb shortening should be based on the axial contractive force of soft tissue. For patients with a lot of scar tissue or severely soft-tissue infection around the bone defect, the limb shortening less than $3 \mathrm{~cm}$ in size was recommended due to the poorly soft-tissue elasticity.

The first challenge of the long segmental tibial defects was to close the gap of the defects. And the next goal was to achieve the docking site union and avoid the additional bone grafts. Various previous studies have been conducted to promote the consolidation of docking site via multiple osteotomy sites to reduce the docking time $[9,15,29-31]$. However, the method may increase the complications correspond to Schanz screws and distraction zone. In our study, five patients who underwent delayed union and nonunion in the bone transport group were treated by the free iliac bone grafts There was no case developing delayed union and non-union in the acute shortening/re-lengthening group. Patients with acute shortening have a shorter time to complete the closure of the gap compared to bone transport, which contributes to the bone union. Furthermore, the compression of the docking site in the re-lengthening process enhances the contact area of the two ends and axial stability, which contributes to the union of the docking site further.

Furthermore, compared with previous studies [18, 22, 29], the llizarov circular external fixator is relatively cumbersome, complex, difficult-learning, time-consuming, and fraught with lots of potential complications. The monolateral rail external fixator used in this study, working on the same principles as Ilizarov circular external fixator, is portable, easy to construct, and has a short learning curve. It is also easy to adjust the sliding clamps to adapt to the transporting bone fragments without altering the nut bolts over the threaded rods, unlike in the llizarov circular external fixator.

The clinical results of the present study manifest that both bone transport and acute shortening/relengthening in the reconstruction of long segmental tibial bone defects caused by infection using a monolateral rail external fixator achieve satisfactory outcomes. Although there were no significant differences between the two groups in the final bone and functional results, the external fixation index, difficulties, and complications were significantly decreased in the acute shortening/re-lengthening group. According to our experience, decisions on the size of limb shortening should be based on the patient's individual soft tissue tension and retraction, but it is recommended that the limb shortening should not exceed $5 \mathrm{~cm}$ unless there is a large soft-tissue defect. Furthermore, radical debridement of the infectious tissues is the most vital step in the reconstruction of bone defects caused by infection. In addition, comprehensive frame understanding, prudent patient selection, appropriate pins insertion, meticulous care, early complications detection, and proper intervention or psychological counseling ensure satisfactory results.

The present study may be limited by the retrospective nature with single-center small sample size, a conservative attitude, therefore, should be adopted regarding the interpretations of our results. Multi- 
centered trials with a larger sample size, life quality assessments, and mental evaluations should be adopted in further investigations.

\section{Conclusion}

Both bone transport and acute shortening/re-lengthening technique in the reconstruction of long segmental tibial bone defect caused by infection using a monolateral rail external fixator can achieve satisfactory clinical outcomes. The acute shortening/re-lengthening can significantly decrease the docking time, external fixation index, difficulties, and complications compared with bone transport.

\section{Declarations}

\section{Acknowledgments}

Not applicable

\section{Authors' Contributions}

FYC and YSL were the patient's first-visit doctors, followed up the patient and contributed to manuscript drafting; $\mathrm{KL}$ and CCF reviewed the literatures and were responsible for the revision of the manuscript for important intellectual content; XM and AY were the patient's surgeons, performed the surgery and were responsible for final approval of the version of the article to be published. All authors read and approved the final manuscript.

\section{Funding}

This study was funded by the grants from National Natural Science Foundation of China (No. 81560357). The funding body was involved in the collection, analysis, and interpretation of data by supporting with salary for the time needed. They were not involved in the design or writing the manuscript

\section{Availability of data and materials}

The datasets analyzed during the current study are available from the corresponding author on reasonable request.

\section{Ethics approval and consent to participate}

All procedures performed in this study were carried out in accordance with the Declaration of Helsinki. This study was approved by the Ethics Committee of The First Affiliated Hospital of Xinjiang Medical University. Written informed consent was obtained from the patient for his data to be recorded in our study.

\section{Consent for publication}


Written informed consent was obtained from all patients for publication of this study and any accompanying images. A copy of the written consent is available for review by the Editor of this journal.

\section{Competing interests}

The authors declare that they have no competing interests.

\section{References}

1. Cattaneo R, Catagni M, Johnson EE: The treatment of infected nonunions and segmental defects of the tibia by the methods of Ilizarov. Clin Orthop Relat Res 1992(280):143-152.

2. Dendrinos GK, Kontos S, Lyritsis $E$ : Use of the llizarov technique for treatment of non-union of the tibia associated with infection. J BONE JOINT SURG AM 1995, 77(6):835-846.

3. Hohmann E, Birkholtz F, Glatt V, Tetsworth K: The "Road to Union" protocol for the reconstruction of isolated complex high-energy tibial trauma. INJURY 2017, 48(6):1211-1216.

4. Heitmann C, Patzakis MJ, Tetsworth KD, Levin LS: Musculoskeletal sepsis: principles of treatment. Instr Course Lect 2003, 52:733-743.

5. Tetsworth K, Cierny GR: Osteomyelitis debridement techniques. Clin Orthop Relat Res 1999(360):8796.

6. Marsh JL, Prokuski L, Biermann JS: Chronic infected tibial nonunions with bone loss. Conventional techniques versus bone transport. Clin Orthop Relat Res 1994(301):139-146.

7. Ashman O, Phillips AM: Treatment of non-unions with bone defects: which option and why? INJURY 2013, 44 Suppl 1:S43-S45.

8. Nauth A, McKee MD, Einhorn TA, Watson JT, Li R, Schemitsch EH: Managing bone defects. J ORTHOP TRAUMA 2011, 25(8):462-466.

9. Robert RS, Weitzman AM, Tracey WJ, Freudigman P, Katz HV, llizarov S: Simultaneous treatment of tibial bone and soft-tissue defects with the llizarov method. J ORTHOP TRAUMA 2006, 20(3):197205.

10. Muller MC, Kramer FJ, Swennen GR, Rahmsdorf M, Haupt C, van Griensven M, Tschernig T, Otto K, Schierle HP: A comparison of two types of free bone grafts as transport discs in segmental distraction for reconstruction of calvarial bone defects: an experimental study. Arch Orthop Trauma Surg 2004, 124(10):665-674.

11. Tukiainen E, Asko-Seljavaara S: Use of the llizarov technique after a free microvascular muscle flap transplantation in massive trauma of the lower leg. Clin Orthop Relat Res 1993(297):129-134.

12. Uzel AP, Lemonne F, Casoli V: Tibial segmental bone defect reconstruction by llizarov type bone transport in an induced membrane. Orthop Traumatol Surg Res 2010, 96(2):194-198.

13. Ilizarov GA: The tension-stress effect on the genesis and growth of tissues. Part I. The influence of stability of fixation and soft-tissue preservation. Clin Orthop Relat Res 1989(238):249-281. 
14. Ilizarov GA: Clinical application of the tension-stress effect for limb lengthening. Clin Orthop Relat Res 1990(250):8-26.

15. Saleh $M$, Rees A: Bifocal surgery for deformity and bone loss after lower-limb fractures. Comparison of bone-transport and compression-distraction methods. J Bone Joint Surg Br 1995, 77(3):429-434.

16. Aronson J, Johnson E, Harp JH: Local bone transportation for treatment of intercalary defects by the llizarov technique. Biomechanical and clinical considerations. Clin Orthop Relat Res 1989(243):7179.

17. Aronson J: Limb-lengthening, skeletal reconstruction, and bone transport with the llizarov method. $J$ BONE JOINT SURG AM 1997, 79(8):1243-1258.

18. Sala F, Thabet AM, Castelli F, Miller AN, Capitani D, Lovisetti G, Talamonti T, Singh S: Bone transport for postinfectious segmental tibial bone defects with a combined ilizarov/taylor spatial frame technique. J ORTHOP TRAUMA 2011, 25(3):162-168.

19. El-Rosasy MA: Acute shortening and re-lengthening in the management of bone and soft-tissue loss in complicated fractures of the tibia. J Bone Joint Surg Br 2007, 89(1):80-88.

20. Song HR, Cho SH, Koo KH, Jeong ST, Park YJ, Ko JH: Tibial bone defects treated by internal bone transport using the llizarov method. INT ORTHOP 1998, 22(5):293-297.

21. Lavini F, Dall'Oca C, Bartolozzi P: Bone transport and compression-distraction in the treatment of bone loss of the lower limbs. INJURY 2010, 41(11):1191-1195.

22. Mahaluxmivala J, Nadarajah R, Allen PW, Hill RA: llizarov external fixator: acute shortening and lengthening versus bone transport in the management of tibial non-unions. INJURY 2005, 36(5):662-668.

23. Eralp L, Kocaoglu M, Celiktas M, Gulsen M: Is acute compression and distraction superior to segmental bone transport techniques in chronic tibial osteomyelitis ? Comparison of Distraction Osteogenesis Techniques. ACTA ORTHOP BELG 2016, 82(3):599-609.

24. Wang H, Wei X, Liu P, Fu YH, Wang PF, Cong YX, Zhang BF, Li Z, Lei JL, Zhang K et al: Quality of life and complications at the different stages of bone transport for treatment infected nonunion of the tibia. Medicine (Baltimore) 2017, 96(45):e8569.

25. Liu Y, Yushan M, Liu Z, Liu J, Ma C, Yusufu A: Complications of bone transport technique using the llizarov method in the lower extremity: a retrospective analysis of 282 consecutive cases over 10 years. BMC Musculoskelet Disord 2020, 21(1):354.

26. Paley D, Catagni MA, Argnani F, Villa A, Benedetti GB, Cattaneo R: Ilizarov treatment of tibial nonunions with bone loss. Clin Orthop Relat Res 1989(241):146-165.

27. Smrke D, Arnez ZM: Treatment of extensive bone and soft tissue defects of the lower limb by traction and free-flap transfer. INJURY 2000, 31(3):153-162.

28. Wu Y, Yin Q, Rui Y, Sun Z, Gu S: llizarov technique: Bone transport versus bone shorteninglengthening for tibial bone and soft-tissue defects. J ORTHOP SCI 2018, 23(2):341-345. 
29. Catagni MA, Azzam W, Guerreschi F, Lovisetti L, Poli P, Khan MS, Di Giacomo LM: Trifocal versus bifocal bone transport in treatment of long segmental tibial bone defects. BONE JOINT J 2019, 101B(2):162-169.

30. Baumgart R, Schuster $B$, Baumgart T: [Callus distraction and bone transport in the treatment of bone defects]. ORTHOPADE 2017, 46(8):673-680.

31. Vesely R, Prochazka V: [Callus Distraction in the Treatment of Post-Traumatic Defects of the Femur and Tibia]. Acta Chir Orthop Traumatol Cech 2016, 83(6):388-392.

32. Aktuglu K, Erol K, Vahabi A: llizarov bone transport and treatment of critical-sized tibial bone defects: a narrative review. J Orthop Traumatol 2019, 20(1):22.

33. Lowenberg DW, Feibel RJ, Louie KW, Eshima I: Combined muscle flap and llizarov reconstruction for bone and soft tissue defects. Clin Orthop Relat Res 1996(332):37-51.

34. Chim $\mathrm{H}$, Sontich JK, Kaufman BR: Free tissue transfer with distraction osteogenesis is effective for limb salvage of the infected traumatized lower extremity. PLAST RECONSTR SURG 2011, 127(6):2364-2372.

35. Tetsworth K, Paley D, Sen C, Jaffe M, Maar DC, Glatt V, Hohmann E, Herzenberg JE: Bone transport versus acute shortening for the management of infected tibial non-unions with bone defects. INJURY 2017, 48(10):2276-2284.

\section{Figures}
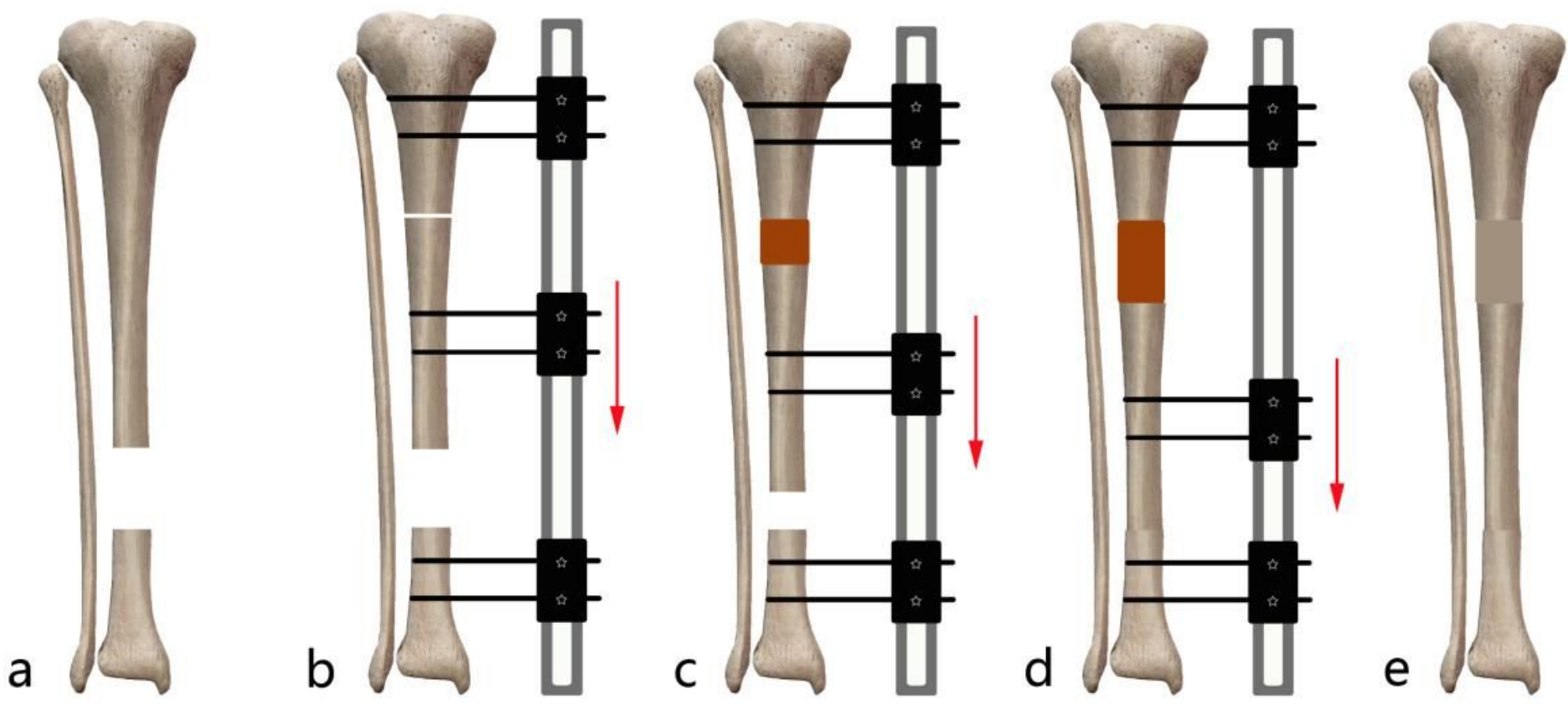

Figure 1

Schematic diagram of the bifocal bone transport technique for the management of the lower third bony segmental defects in the tibia (from left to right). 

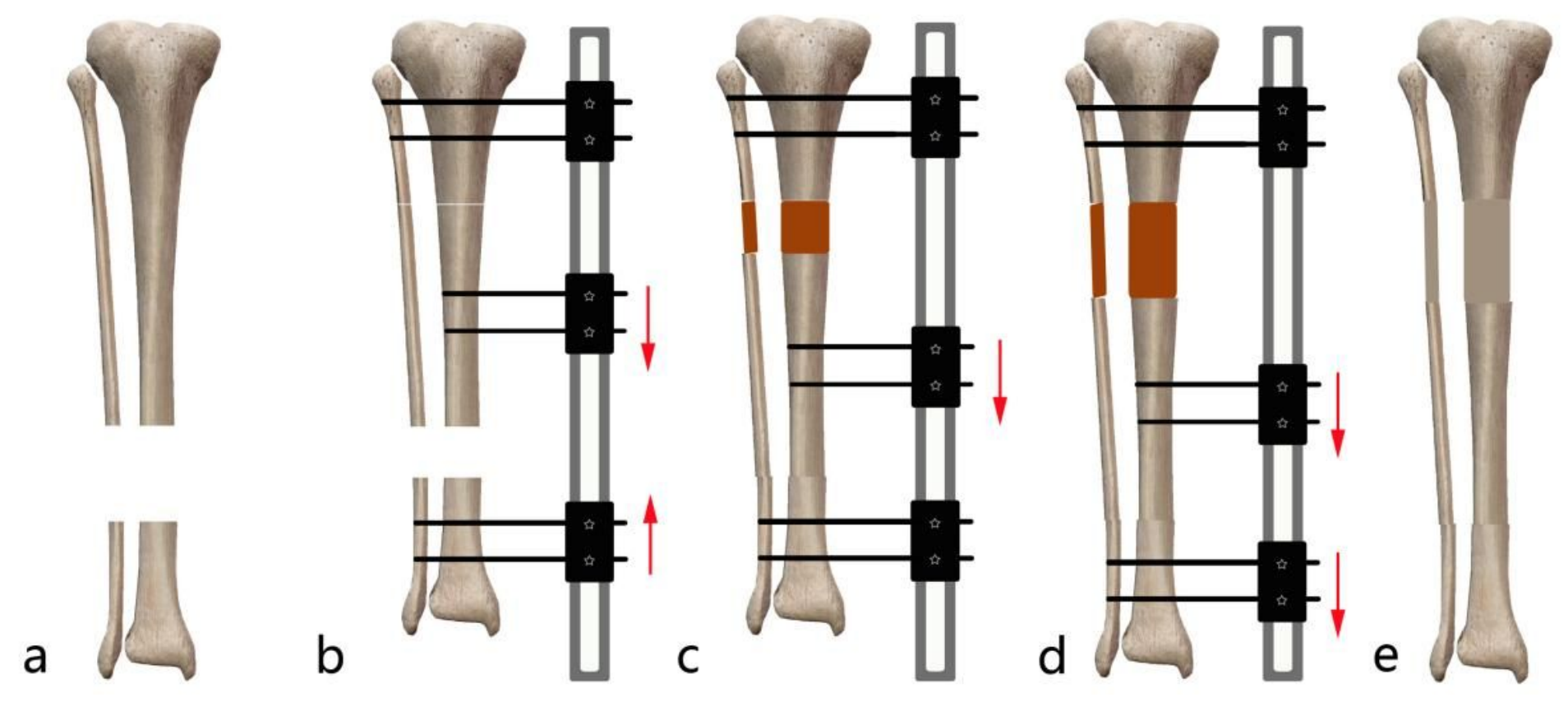

Figure 2

Schematic diagram of the acute shortening/re-lengthening for the management of the lower third bony segmental defects in the tibia (from left to right). 


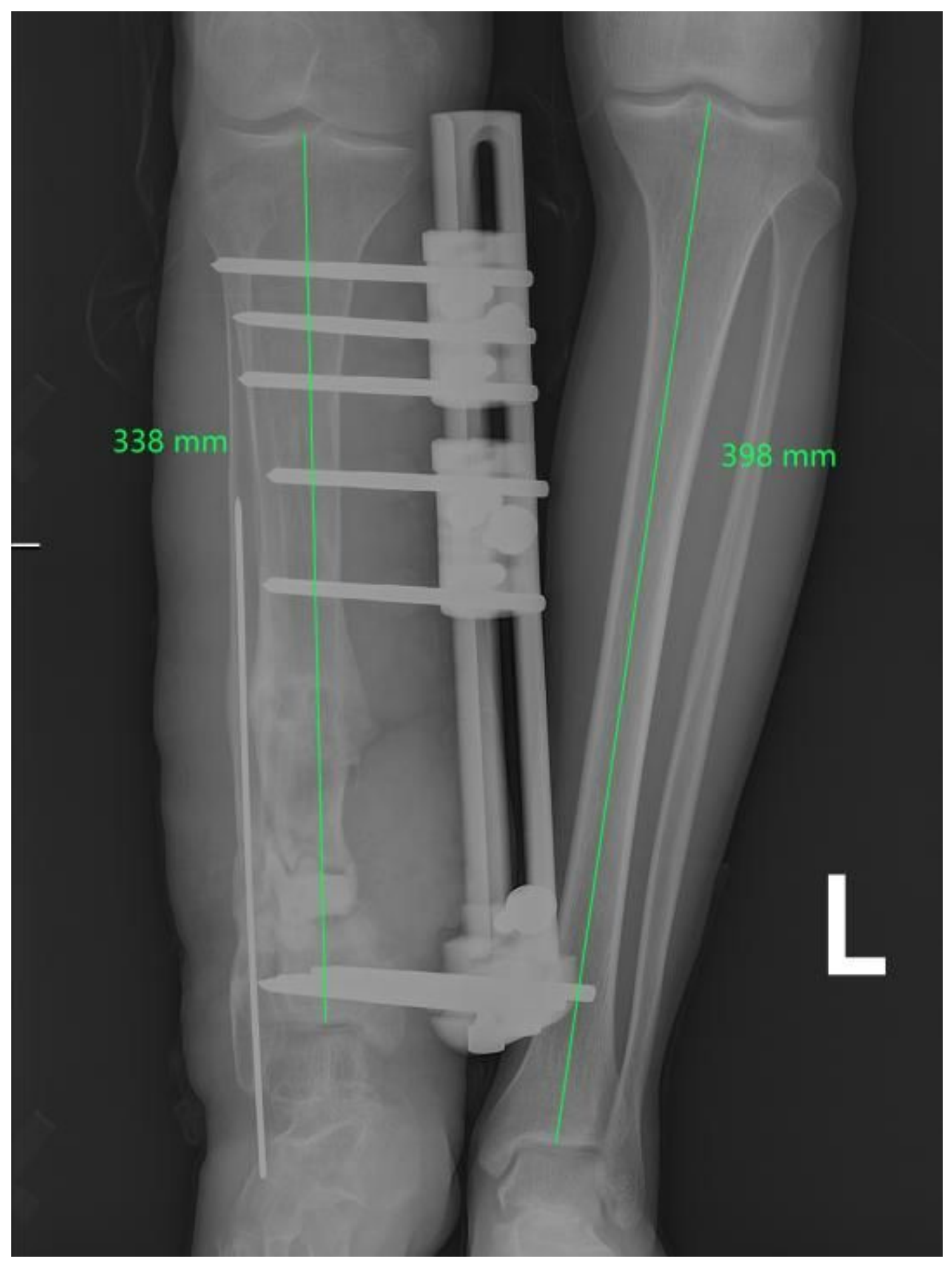

\section{Figure 3}

A acute shorting of about $6 \mathrm{~cm}$ was applied to the right lower limb, and the remaining bone defect was filled with an antibiotic-impregnated cement spacer. The right tibia length $(338 \mathrm{~mm})$ and the left tibia length $(398 \mathrm{~mm})$. 

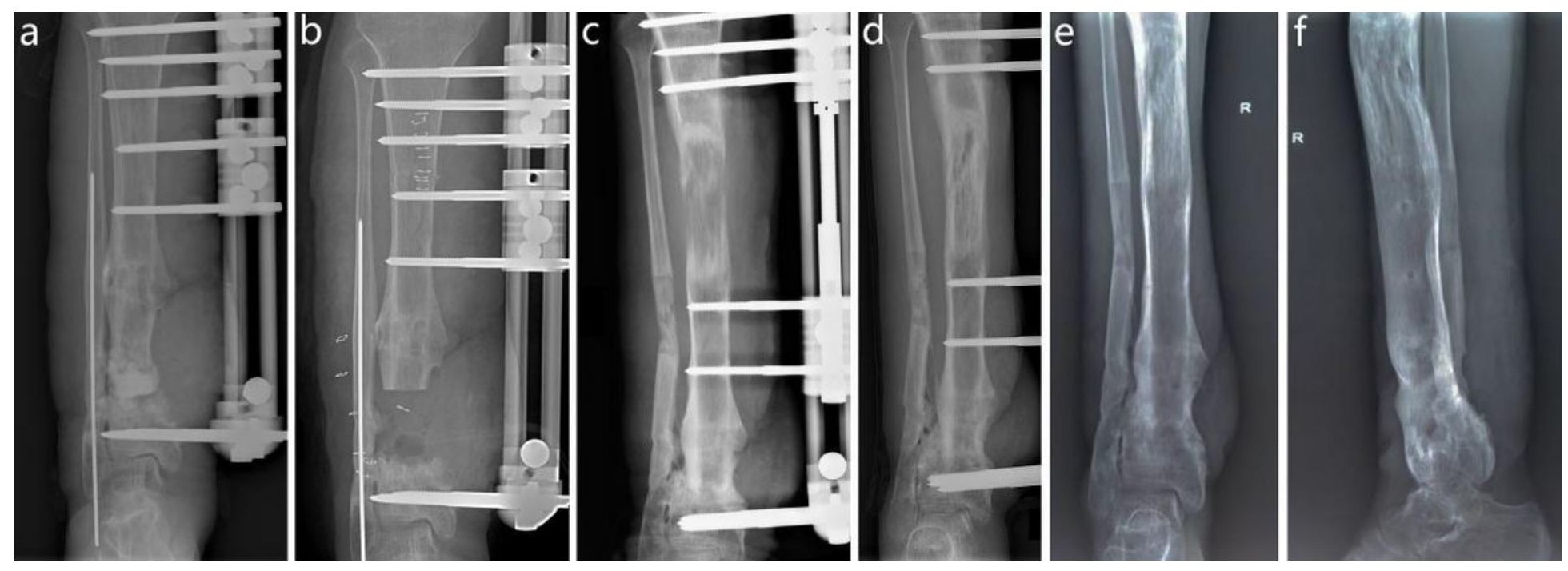

\section{Figure 4}

The process of acute shortening/re-lengthening. (a) A monolateral external fixation was performed with an acute limb shortening. (b) The cement spacer was removed and the bone transport was started. (c, d) The docking site was met and the limb lengthening was performed. $(e, f)$ The anteroposterior and lateral radiographs of the tibia after external fixator was removed.

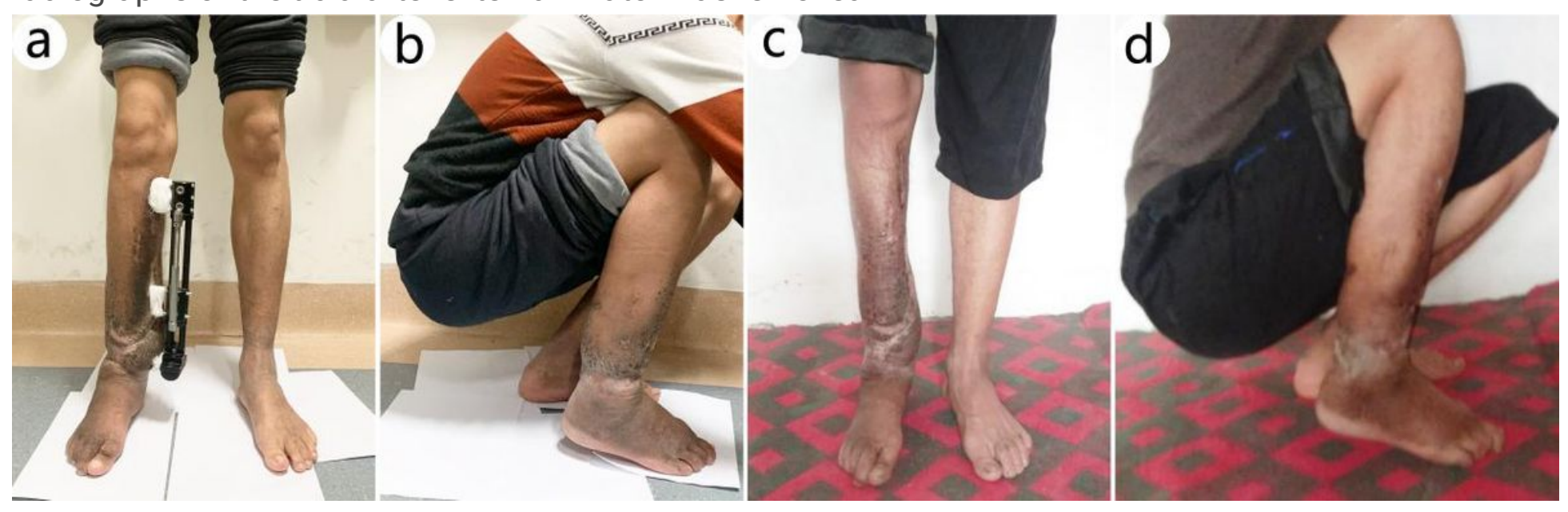

\section{Figure 5}

Length and function of the injured limb. $(a, b)$ One year after the surgery of monolateral external fixation: there was no discrepancy in length with satisfactory knee joint mobility. (c, d) Two years after the surgery: a satisfactory reconstruction was followed. 